\title{
Work Related Neck Pain and Its Associated Factors among Registered Female Nurses Who Are Computer Users in Universiti Kebangsaan Malaysia Medical Centre
}

\author{
Dr. Mohammed Younus Mustafa ${ }^{1}$, Associate Prof. Dr. Rosnah Sutan ${ }^{2}$ \\ ${ }^{1}$ Community Health Science, Collegeof Medicine, National University of Malaysia, Malaysia \\ ${ }^{2}$ Community Health Science, Collegeof Medicine, National University of Malaysia, Malaysia
}

\begin{abstract}
Work related neck pain is common problem in nurses, especially among those who are intensive computer users. It is generally agreed that the its etiology is multidimensional which is associated with, and influenced by a complex array of socio-demographic, work related, lifestyle, ergonomic and psychosocial factors. Across sectional study was conducted to in August-October 2012 in University Kebangsaan Malaysia Medical Centre, Malaysia to estimate the 1 month and 12 months prevalence rates of neck pain among registered female nurses and to determine which socio-demographic, work related, lifestyle, ergonomic and psychosocial factors are associated with 12 months prevalence rate. A total of 250 respondents have been selected by using stratified sampling method. Data was collected via self-reporting modified Dutch musculoskeletal questionnaire. The response rate was (96.8\%) and data was analyzed by using SPSS version 19. Age of respondents was around 18 to 52 years old with the mean age of $32.31 \pm 9.27$ years. The point and 12 month period prevalence rates of neck pain in registered female nurses were (36\%) and (45.5\%) respectively. Majority of respondents were Malay (97.9\%), married (72.3\%), not doing physical exercise (69\%), having highest education, Diploma in Nursing (88.8\%) and working in night shifts (76.9\%). Generally, the respondents were reported that their neck pain was associated with working hours on computer for more than 4 hours (56.7\%); neck bending (56.4\%) and Personnel shortage (53.2\%). In bivariate; Chi square analysis, the result of present study indicated that there were seven factors significantly associated with neck pain i.e. age, BMI, physical exercises, night shifts, neck bending, prolonged working hours on computer and personnel shortage. Further analysis, by using multiple logistic regression showed that age groups 30-39 ( $p=0.011$, 95\% CI 1.2335.5044) and 40-49 ( $p=0.040$, 95\% CI 1.041- 5.311), physical exercises $(p=0.025$, 95\% CI 1.106- 4.384), working time on computer $(p=0.029,95 \%$ CI 1.075-3.725), night shifts $(p=0.001,95 \%$ CI 0.938-3.144), personnel shortage ( $p=0.005,95 \%$ CI 1.334-4.908) and neck bending ( $p=0.013,95 \%$ CI 1.192-4.299) were significant predictors to work related neck pain.The results of present study indicated that socio-demographic, lifestyle, ergonomic factors and some of psychosocial variables were associated with neck pain. These association patterns suggest also opportunities for intervention strategies in order to stimulate an ergonomic work place setting to improve physical exercises awareness and to increase a positive psychosocial work environment.
\end{abstract}

Keywords: Ergonomic, Neck pain, Nurses, Psychosocial, Socio-demographic.

\section{Introduction.}

The non communicable diseases have been dramatically increased all over the world especially musculoskeletal diseases which considered one of the major causes of morbidity throughout the world, that even could be the second only to respiratory disorders as a cause of short and long medical leave from work in many countries. Their direct and indirect cost is considerable and their management utilizes a significant part of the gross national product of many countries ${ }^{1}$.

Work related neck pain is one of the important components of work related musculoskeletal disorders; WMSDs and occupational health issues. It is a leading cause for disability and activity limitations and absenteeism of the workers that in turn could affect gross national production and could form a big economic burden for any country even though with small prevalence rates, for instance prevalence rates of work related neck pain were $27.1 \%$ in Norway and $47.8 \%$ in Canada while annul activity limitations of workers' costs were $11 \%$ and $14.1 \%$ respectively ${ }^{2}$.

Work related neck pain is one of the common musculoskeletal disorders that affects millions of workers throughout the world across variant works or sectors of services like nurses and office workers especially among those who are intensive computer users and keeping their neck in awkward postures or moving their neck repetitively when use the computer ${ }^{3+4}$.

The aim of this research is to study the point and 12 month period prevalence rates of work related neck pain among registered female nurses in Universiti Kebangsaan Malaysia Medical Centre and to determine which 
socio-demographic, work related, lifestyle, ergonomic and psychosocial factors are associated with 12 months prevalence rate.

\section{Methodology.}

This was a cross sectional study which conducted at Universiti Kebangsaan Malaysia Medical Centre from August until October 2012. Sample size was calculated based on the calculation from Ijmker $S^{5}$, with confident interval $95 \%$, the prevalence rate of the neck pain from the previous study was $42 \%$ among women and $24 \%$ among men; the minimum sample size would be 250 nurses. We managed to recruit 250 registered female nurses by using stratified sampling method to calculate the number of nurses from each department as participants then simple random sampling was applied. Data was collected by self-adminstrated questionnaire. The questionnaire contained of 37 items which related to socio-demographic, work related, lifestyle, ergonomic and psychosocial risk factors of neck pain. Likert Scale was used to score the psychosocial factors questions with four response categories (usually, all the time, sometimes and never); who answered (usually or all the time) was considered "yes" and who answered (sometimes or never) was considered "no". Other variables categorization into two groups by using "median" in SPSS analysis as a cut-off point between them. Data was analyzed using Statistical Package for Social Science (SPSS) programme version 19. Normality tests were done and all of the quantitative data were found to be normally distributed. Therefore, statistical analysis which used in this study was parametric test such as Pearson Correlation and Chi square test. For further analysis, multiple logistic regression was done to predict the factors that influence neck pain.

\section{Results.}

The response rate in this study was $96.8 \%$ (242 out of 250). From the analysis to determine the work related neck pain prevalence rate; $36 \%$ of respondents had point prevalence rate of neck pain and $45.5 \%$ had period prevalence rate of neck pain.

\section{Neck pain severity.}

Table 1 shows the self-rated neck pain severity in the last 1 month of present study from 15 of September to 15 of October 2012 generally was mild $39.1 \%$, moderate $51.7 \%$ and severe $9.2 \%$. And according to working departments, the highest mild pain was in surgical departments 76.2 , the highest moderate pain was in medical and anesthesiology \& ICU departments $42.9 \%$, and the highest severe pain was in emergency unit $20 \%$.

\section{Socio-demographic characteristics.}

Respondents socio-demographic characteristics which have been studied were weight and height to calculate BMI, also age, race and marital status. Their age ranged from 18-52 years old and the mean age was $32.31 \pm 9.27$ years. Most of them were married $72.3 \%$ when compared to $27.7 \%$ were single (unmarried, divorce and widows). In terms of age, it have been divided into 4 ethnic groups; Malay, Chinese, Indian and others; and the response rate were $97.9 \%, 0.4 \%, 1.2 \%$ and $0.4 \%$ respectively. And In terms of age, it have been divided into 4 categories; (18-29), (30-39), (40-49) and (50-59) years age-groups ${ }^{3} ;$ and the response rate were $44.2 \%, 31.4 \%$, $20.7 \%$ and $3.7 \%$ respectively. And in terms of BMI, also it have been divided into 4 categories according to Asian BMI cut-off points into mormal, underweight, overweight and obese; and the response rate were 29.3\%, $3.7 \%, 31 \%$ and $36 \%$ respectively. Tables 2 and 3 show the demographic characteristics of respondents.

\section{Lifestyle characteristics.}

Respondents lifestyle characteristics which have been studied were smoking and physical exercises. In terms of smoking, only 3 were smokers $1.2 \%$. In terms of physical exercises, most of respondents were not doing physical exercises $69 \%$ and those who were doing $31 \%$, only $24 \%$ (18 out of 75 ) of them were doing physical exercises regularly more than 3 times per week $6+7$. Table 3 shows the lifestyle characteristics of respondents.

\section{Work related characteristics.}

Respondents work related characteristics which have been studied were working departments, night shifts, educational level, daily working time, employment duration and medical leave due to neck pain in preceding 12 months. In terms of working departments, in present study, total 17 department in UKMMC have been categorized into 5 departments; medical department (internal medicine, pediatric, family medicine, psychiatry, infectious controlling unit, radiotherapy \& oncology, continuous medical education and clinic Warga), surgical department (general surgery, obstetric \& gynecology, orthopedic \& traumatology, ophthalmology, maxillofacial and ENT), emergency department, anesthesiology \& ICU department and nursing management department, and the response rate were $25.2 \%, 29.8 \%, 19.8 \%, 21.1 \%$ and $4.1 \%$ respectively. In terms of night shifts, $76.9 \%$ of respondents were doing night shifts. In terms of educational level, $88.8 \%$ of 
respondents had Diploma in Nursing. In terms of daily working time and according to median cut-off point, $75.6 \%$ of respondents were working less than 9 hours. In terms of employment duration and according to median cut-off point, $75.6 \%$ of respondents were working less than 4 years $54.5 \%$. In terms of medical leave due to neck pain, it range from 1 to 3 day among respondents who reported neck pain in preceding 12 months $10.7 \%$. Tables 2 and 4 show the work related characteristics of respondents.

\section{Ergonomic characteristics.}

Respondents ergonomic characteristics which have been studied were top of computer display's at eye level, distance of computer's display at arm's length, position of computer's display, arm resting during working on computer,support such as copy holder using during working on computer, working hours on computer per day, neck twisting, frequency of neck twisting, neck bending and frequency of neck bending. In terms of top of computer display's, $52.7 \%$ was not at respondents eye level. In terms of distance of computer's display, $63.6 \%$ was not in range of respondents own arm's length. In terms of position of computer's display, $51.7 \%$ was not placed in front of respondents. In terms of arm resting, 55.7\% of respondents were rested their arms. In terms of copy holder using, $82.6 \%$ was not used by respondents. In terms of working hours on computer and according to median cut-off point, $57 \%$ of respondents were working less than 4 hours on computer. In terms of neck twisting and frequency of neck twisting, $41.2 \%$ and 35.4\% (34 out of 96 who twisted neck) of respondents twisted the neck and not frequently respectively. In terms of neck bending and frequency of neck bending, $42.4 \%$ and $40.6 \%$ (41 out of 101 who bent neck) of respondents bent the neck and not frequently respectively. Table 5 shows the ergonomic characteristics of respondents.

\section{Psychological characteristics.}

Respondents psychological characteristics which have been studied were work satisfaction, personnel shortage, mental tiredness at the end of the workday, break-time sufficiency, perceived co-workers support, perceived supervisors support, perceived co-workers friendly dealing and perceived supervisors friendly dealing. In terms of work satisfaction, $58.6 \%$ of respondents were satisfied. In terms of personnel shortage, $64.7 \%$ of respondents reported there was a shortage in personnel that caused a work overload. In terms of mental tiredness, $85.2 \%$ of respondents reported they did not have it at the end of the workday. In terms of break-time, $72.1 \%$ of respondents reported that it was not sufficient. In terms of co-workers support, $58.9 \%$ of respondents perceived that it was not enough. In terms of supervisors support, $76.8 \%$ of respondents perceived that it was enough. In terms of co-workers and supervisors dealing, $75.3 \%$ and $72.1 \%$ respectively of respondents perceived that it was friendly. Table 6 shows the psychological characteristics of respondents.

\section{Association between neck pain and socio-demographic $\&$ lifestyle factors.}

Table 7 showed Chi square test for sociodemographic and lifestyle characteristic of nurses and neck pain. The results revealed that there were a significant associations between age, BMI and physical exercises, and neck pain ( $\mathrm{p}$ value $<0.05$ ). In terms of physical exercises, the nurses who did not do physical exercises $52.1 \%$ of them had more neck pain when compared to those who did, $30.7 \%$.

\section{Association between neck pain and work related factors.}

Table 8 showed Chi square test for work related characteristic of nurses and neck pain. The results revealed that there was a significant associations between night shifts and neck pain ( $p$ value $<0.05$ ). The nurses who did night shifts $51.1 \%$ of them had more neck pain when compared to those who did not, $26.8 \%$.

\section{Association between neck pain and ergonomic factors.}

Table 9 showed Chi square test for ergonomic characteristic of nurses and neck pain. The results revealed that there were a significant associations between working hours on computer and neck bending, and neck pain ( $\mathrm{p}$ value $<0.05$ ). In terms of working hours on computer, the nurses who used computer for prolonged hours; more than 4 hours according to cut-off point in this study, 56.7\% of them had more neck pain when compared to those who worked for less than 4 hours, $30.7 \%$. In terms of neck bending, the nurses who bent their necks $56.4 \%$ of them had more neck pain when compared to those who did not bend, $36.5 \%$.

\section{Association between neck pain and psychosocial factors.}

Table 10 showed Chi square test for psychosocial characteristic of nurses and neck pain. The results revealed that there was a significant association between personnel shortage and neck pain ( $\mathrm{p}$ value $<0.05$ ). The nurses who were exhausted due to work overload because of personnel shortage, $53.2 \%$ had more neck pain when compared to those who were not, $31 \%$. 


\section{Multivariate Analysis}

In order to determine which of the study variables best explained the variation in neck pain, multiple logistic regressions (backward LR technique) was done. All seven variables which associated significantly with neck pain in bivariate analysis by using Chi square test entered in the logistic regression. The significant predictors of neck pain in this model after control of confounders were (30-39) and (40-49) years age groups ( $\mathrm{p}=$ $0.011)$ and $(p=0.040)$ respectively, physical exercises $(\mathrm{p}=0.025)$, working time on computer $(\mathrm{p}=0.029)$, night shifts $(\mathrm{p}=0.001)$, personnel shortage $(\mathrm{p}=0.005)$ and neck bending $(\mathrm{p}=0.013)$, table 11. And the total model was significant $(p<0.000)$ and accounted for $33.1 \%$ of the variance in neck pain (Nagelkerke R Square $=0.331$ ). The Hosmer and Lemeshow Test indicated a good fit $(\mathrm{p}=0.425)$.

Registered female nurses in age group (30-39) when compared to those who were in age group (18-29), shows 2.49 (95\% CI 1.233- 5.5044) times more likely to have neck pain, also who were in age group (40-49) when compared to those who were in age group (18-29) 2.35 (95\% CI 1.041- 5.311) times more likely to have neck pain, while who were in age group (50-59) fifth times less likely have neck pain.

Registered female nurses were not doing physical exercises 2.20 (95\% CI 1.106- 4.384) times more likely to have neck pain when compared to those who were doing. Registered female nurses were working on computer more than 4 hours 2.00 (95\% CI 1.075-3.725) times more likely to have neck pain when compared to who were not.

Registered female nurses who were working at night shifts 2.39 (95\% CI 0.938-3.144) times more likely to have neck pain when compared to who were not. Registered female nurses who reported personnel shortage 2.56 (95\% CI 1.334-4.908) times more likely to have neck pain when compared to who did not. Finally registered female nurses were bending their necks 2.27 (95\% CI 1.192-4.299) times more likely to have neck pain when compared to who were not.

\section{Tables.}

Table 1 Neck pain severity in the last 1 month in departments of UKMMC.

\begin{tabular}{lcccc}
\hline Departments & n & Mild n(\%) & $\begin{array}{c}\text { Neck Pain Severity } \\
\text { Moderate n(\%) }\end{array}$ & Severe n(\%) \\
\hline Medical departments & 21 & $10(47.6 \%)$ & $9(42.9 \%)$ & $2(9.5 \%)$ \\
Surgical departments & 21 & $16(76.2 \%)$ & $4(19 \%)$ & $1(4.8 \%)$ \\
Anesthesiology \& ICU & 21 & $11(52.4 \%)$ & $9(42.9 \%)$ & $1(4.8 \%)$ \\
Nursing Management & 19 & $10(52.6 \%)$ & $8(42.1 \%)$ & $1(5.3 \%)$ \\
Emergency Unit & 5 & $3(60 \%)$ & $1(20 \%)$ & $1(20 \%)$ \\
\hline
\end{tabular}

Table 2. Descriptive statistics of registered female nurses in UKMMC ( $n=242)$.

\begin{tabular}{lllll}
\hline Variables & Minimum & Maximum & Mean & S.D \\
\hline Age $($ year) & 18 & 52 & 32.31 & 9.27 \\
Height $(\mathrm{cm})$ & 142 & 182 & 158.01 & 8.07 \\
Weight $(\mathrm{kg})$ & 40 & 116 & 65.01 & 15.14 \\
Body mass index $\left(\mathrm{kg} / \mathrm{m}^{2}\right)$ & 17.26 & 42.46 & 25.88 & 5.11 \\
Daily Working time (hours/day) & 7 & 14 & 8.82 & 1.35 \\
Working time on computer (hours/day) & 3 & 6 & 4.39 & 0.96 \\
Employment duration (years) & 1 & 17 & 4.78 & 2.92 \\
Night shifts no. (shifts/week) & 1 & 3 & 1.7 & 0.73 \\
\hline
\end{tabular}

* Among who did night shifts, $\mathrm{n}=186$.

Table 3 Socio-demographic and lifestyle factors of registered female nurses in UKMMC $(n=242)$.

\begin{tabular}{lcc}
\hline Factors & n & \% \\
\hline Race & & \\
Malay & 237 & 97.9 \\
Chinese & 1 & 0.4 \\
Indian & 3 & 1.2 \\
Others & 1 & 0.4 \\
Marital Status & & \\
$\quad$ Married & 175 & 72.3 \\
Unmarried & 67 & 27.7 \\
Age $\quad$ & & \\
18-29 years & 107 & 44.2 \\
30-39 years & 76 & 31.4 \\
40-49 years & 50 & 20.7 \\
50-59 years & 9 & 3.7
\end{tabular}


BMI

$\begin{array}{lll}\text { Normal } & 71 & 29.3\end{array}$

$\begin{array}{lll}\text { Underweight } & 9 & 3.7\end{array}$

$\begin{array}{lll}\text { Overweight } & 75 & 31\end{array}$

Obese $\quad \begin{array}{lll} & 36\end{array}$

Smoking

$\begin{array}{llll}\text { Yes } & 3 & 1.2\end{array}$

$\begin{array}{lll}\text { No } & 239 & 98.8\end{array}$

Physical Exercises

$\begin{array}{lll}\text { Yes } & 75 & 31\end{array}$

$\begin{array}{lll}\text { No } & 167 & 69\end{array}$

Physical Exercises/week ${ }^{*}$

$\begin{array}{lll}\text { More than } 3 \text { times a week } & 18 & 24\end{array}$

Less than 3 times a week

$57 \quad 76$

* This is only among who did physical exercises, $n=75$.

Table 4 Work related characteristics of registered female nurses in UKMMC $(\mathrm{n}=\mathbf{2 4 2})$.

\begin{tabular}{|c|c|c|}
\hline Factors & $\mathbf{n}$ & $\%$ \\
\hline \multicolumn{3}{|l|}{ Working Departments } \\
\hline Medical departments & 61 & 25.2 \\
\hline Surgical departments & 72 & 29.8 \\
\hline Anesthesiology \& ICU & 48 & 19.8 \\
\hline Nursing management & 51 & 21.1 \\
\hline Emergency unit & 10 & 4.1 \\
\hline \multicolumn{3}{|l|}{ Night Shifts } \\
\hline Yes & 186 & 76.9 \\
\hline No & 56 & 23.1 \\
\hline \multicolumn{3}{|l|}{ Educational Level } \\
\hline Diploma in nursing & 215 & 88.8 \\
\hline Degree in nursing & 27 & 11.2 \\
\hline \multicolumn{3}{|l|}{ Daily Working Time } \\
\hline$>9$ hours & 59 & 24.4 \\
\hline$\leq 9$ hours & 183 & 75.6 \\
\hline \multicolumn{3}{|l|}{ Employment Duration } \\
\hline$>4$ years & 110 & 45.5 \\
\hline$\leq 4$ years & 132 & 54.5 \\
\hline \multicolumn{3}{|c|}{ Medical Leave Due to Neck Pain } \\
\hline Yes & 26 & 10.7 \\
\hline No & 216 & 89.3 \\
\hline \multicolumn{3}{|l|}{ Job Change Due to Neck Pain } \\
\hline Yes & 11 & 4.5 \\
\hline No & 231 & 95.5 \\
\hline \multicolumn{3}{|l|}{ Temporary Contract } \\
\hline Yes & 14 & 5.8 \\
\hline No & 228 & 94.2 \\
\hline \multicolumn{3}{|l|}{ Working in Private Sector } \\
\hline Yes & 50 & 20.7 \\
\hline No & 192 & 79.3 \\
\hline \multicolumn{3}{|c|}{ Neck Pain Start during Present Work } \\
\hline Yes & 140 & 57.9 \\
\hline No & 102 & 42.1 \\
\hline \multicolumn{3}{|c|}{ Neck Pain Associated with Work } \\
\hline Yes & 166 & 71.5 \\
\hline No & 69 & 28.5 \\
\hline \multicolumn{3}{|c|}{ Neck Pain Hindered Activities of Work } \\
\hline Yes & 40 & 16.5 \\
\hline No & 202 & 83.5 \\
\hline
\end{tabular}


Table 5 Ergonomic factors of registered female nurses in UKMMC.

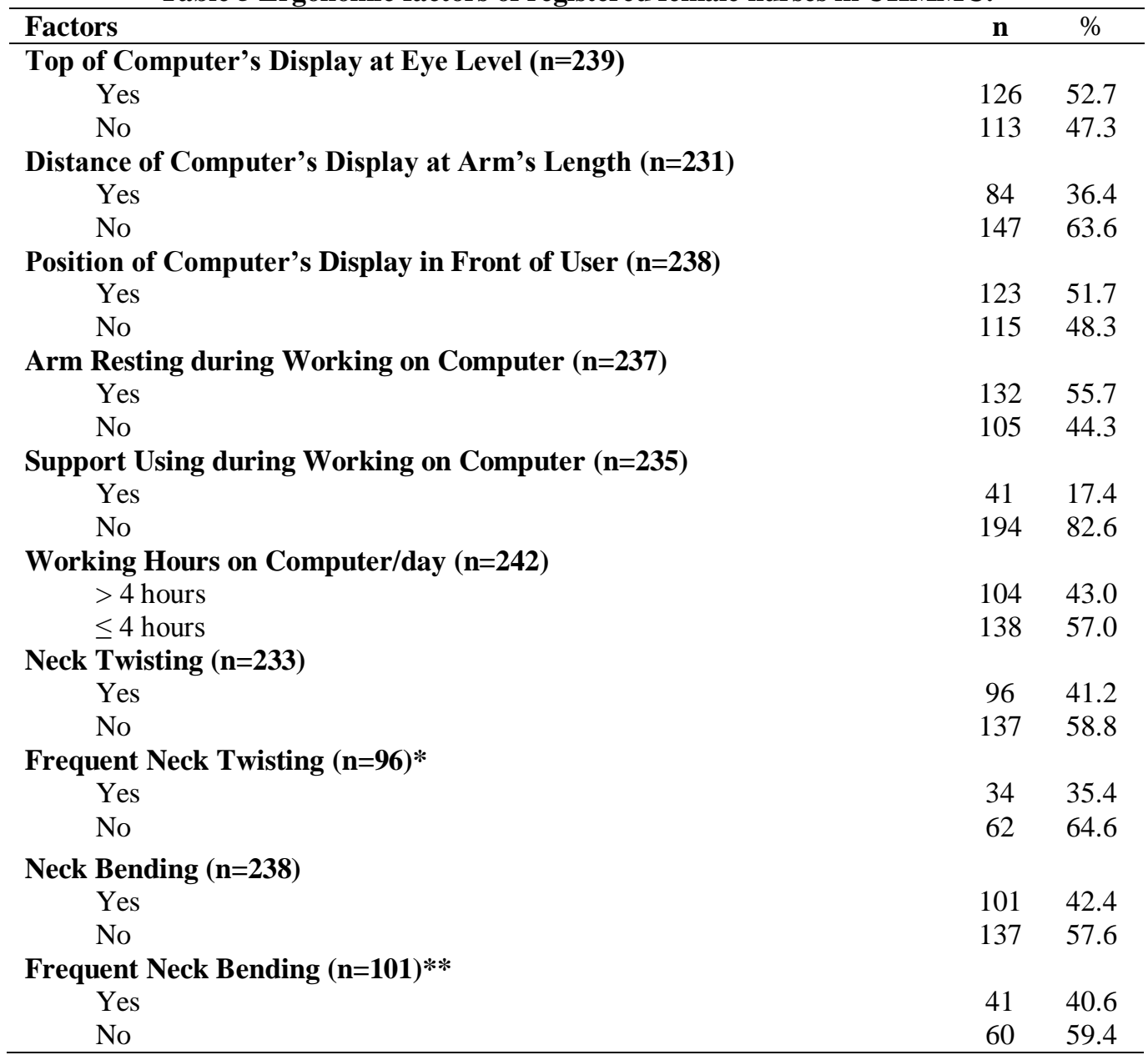

* Among nurses who twisted their necks. ** Among nurses who bent their necks.

Table 6 Psychosocial characteristics of registered female nurses in UKMMC.

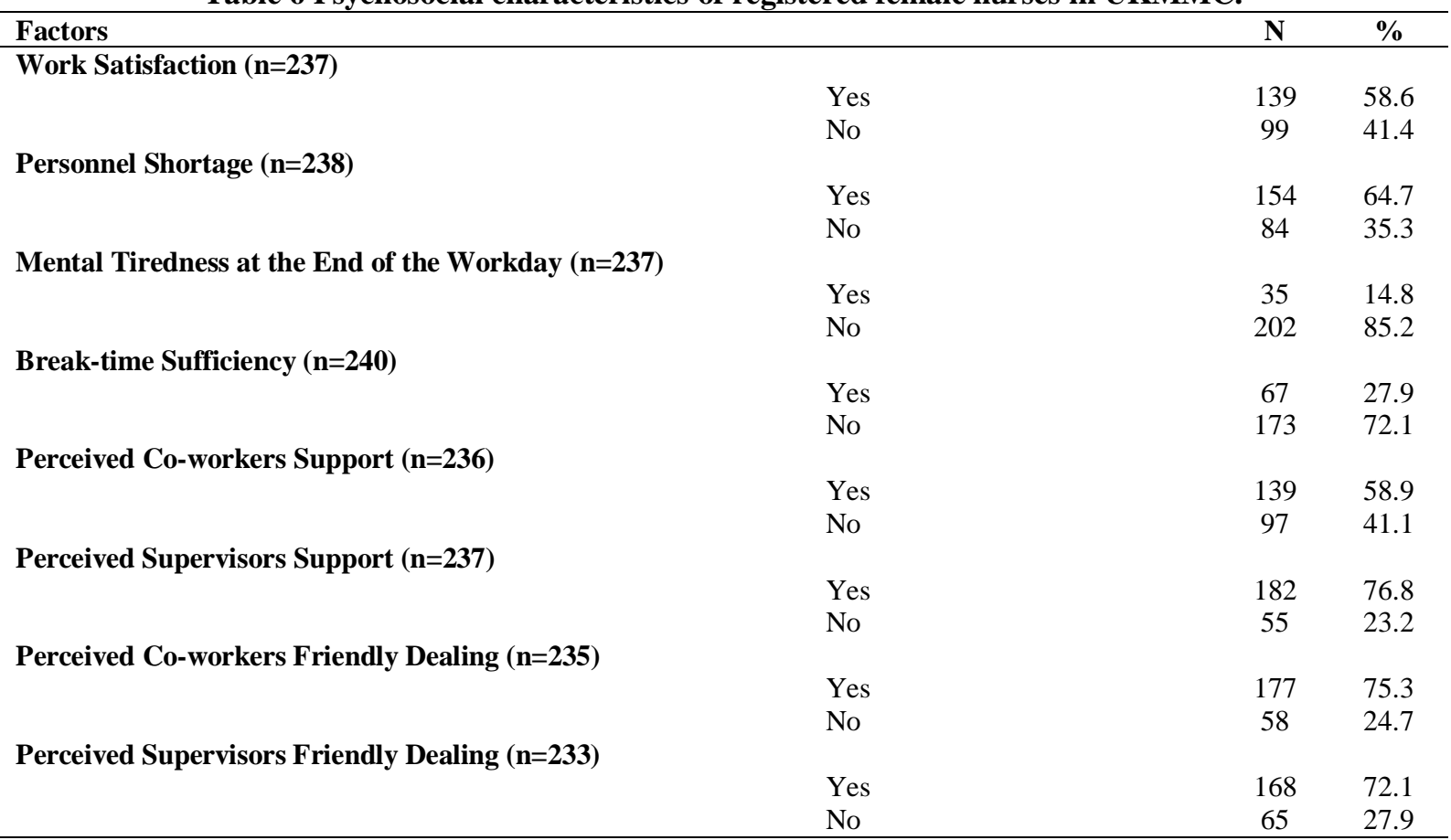


Work Related Neck Pain And Its Associated Factors Among Registered Female Nurses Who Are

Table 7 Association between neck pain and socio-demographic \& lifestyle factors.

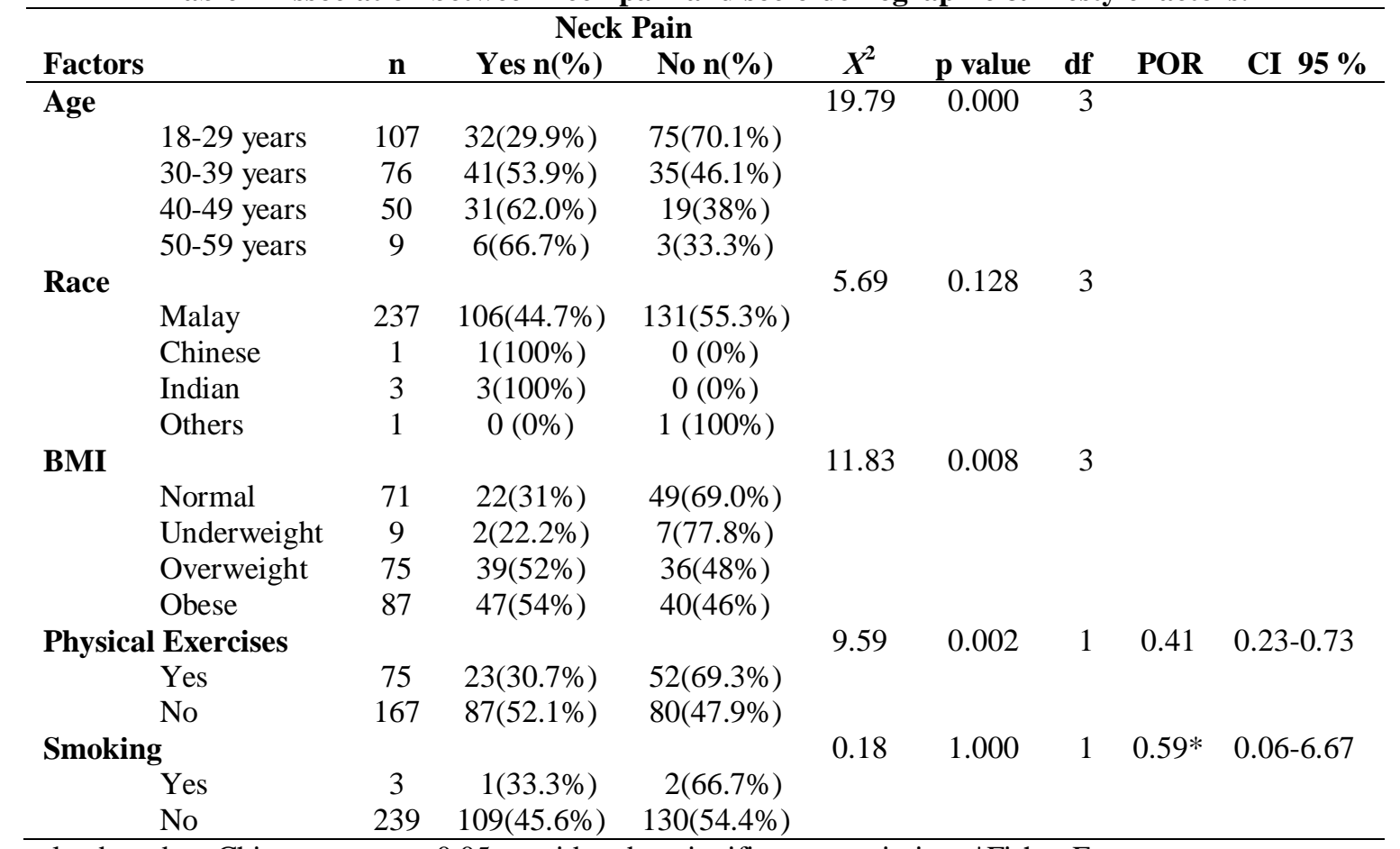

$\mathrm{p}$ value based on Chi square test, $<0.05$ considered as significant association. *Fisher Exact test.

Table 8 Association between neck pain and work related factors.

\begin{tabular}{|c|c|c|c|c|c|c|c|c|}
\hline \multirow[b]{2}{*}{ Factors } & \multicolumn{4}{|c|}{ Neck Pain } & \multirow[b]{2}{*}{$p$ value } & \multirow[b]{2}{*}{ df } & \multirow[b]{2}{*}{ POR } & \multirow[b]{2}{*}{ CI $95 \%$} \\
\hline & $\mathbf{n}$ & Yes n $(\%)$ & No $n(\%)$ & $X^{2}$ & & & & \\
\hline $\begin{array}{l}\text { Working } \\
\text { departments }\end{array}$ & & & & 7.79 & 0.100 & 4 & & \\
\hline Medical & 61 & $24(39.3 \%)$ & $37(60.7 \%)$ & & & & & \\
\hline Surgical & 72 & $41(56.9 \%)$ & $31(43.1 \%)$ & & & & & \\
\hline A. \& ICU & 48 & $21(43.8 \%)$ & $27(56.2 \%)$ & & & & & \\
\hline Nursing & 51 & $18(35.3 \%)$ & $33(64.7 \%)$ & & & & & \\
\hline Emergency & 10 & $6(60 \%)$ & $4(40 \%)$ & & & & & \\
\hline $\begin{array}{l}\text { Employment } \\
\text { duration/year }\end{array}$ & & & & 3.29 & 0.092 & 1 & 1.61 & $0.97-2.67$ \\
\hline$>4$ years & 110 & $57(51.8 \%)$ & $53(48.2 \%)$ & & & & & \\
\hline$\leq 4$ years & 132 & $53(40.2 \%)$ & $79(59.8 \%)$ & & & & & \\
\hline Night shifts/week & & & & 10.24 & 0.001 & 1 & 2.86 & $1.48-5.51$ \\
\hline Yes & 186 & $95(51.1 \%)$ & $91(48.9 \%)$ & & & & & \\
\hline No & 56 & $15(26.8 \%)$ & $41(73.2 \%)$ & & & & & \\
\hline
\end{tabular}

p value based on Chi square test, $<0.05$ considered as significant association.

Table 9 Association between neck pain and ergonomic factors.

\begin{tabular}{|c|c|c|c|c|c|c|c|c|}
\hline \multirow[b]{2}{*}{ Factors } & \multicolumn{4}{|c|}{ Neck Pain } & \multirow[b]{2}{*}{ p value } & \multirow[b]{2}{*}{ df } & \multirow[b]{2}{*}{ POR } & \multirow[b]{2}{*}{ CI $95 \%$} \\
\hline & $\mathbf{n}$ & Yes n $(\%)$ & No n $(\%)$ & $X^{2}$ & & & & \\
\hline Display's Height & & & & 0.08 & 0.796 & 1 & 0.93 & $0.56-1.55$ \\
\hline At eye level & 113 & $50(44.2 \%)$ & $63(55.8 \%)$ & & & & & \\
\hline Not at eye level & 126 & $58(46 \%)$ & $68(54 \%)$ & & & & & \\
\hline Display's Distance & & & & 0.16 & 0.783 & 1 & 1.12 & $0.65-1.92$ \\
\hline At arm's length & 84 & $36(42.9 \%)$ & $48(57.1 \%)$ & & & & & \\
\hline Not arm's length & 187 & $67(45.6 \%)$ & $80(54.4 \%)$ & & & & & \\
\hline Display's Position & & & & 0.95 & 0.362 & 1 & 1.29 & $0.78-2.16$ \\
\hline In front & 123 & $51(41.5 \%)$ & $72(58.5 \%)$ & & & & & \\
\hline Not In front & 115 & $55(47.8 \%)$ & $60(52.2 \%)$ & & & & & \\
\hline Arm Resting & & & & 0.20 & 0.695 & 1 & 0.89 & $0.53-1.49$ \\
\hline Yes & 132 & $59(44.7 \%)$ & $73(55.3 \%)$ & & & & & \\
\hline No & 105 & $50(47.6 \%)$ & $55(52.4 \%)$ & & & & & \\
\hline
\end{tabular}


Work Related Neck Pain And Its Associated Factors Among Registered Female Nurses Who Are

Support Using

Yes

No

Working hours on

computer/day

$>4$ hours

$\leq 4$ hours

Neck Twisting

Yes

No

Twisting Frequency* Yes

No

Neck Bending Yes

No

Bending

Frequency** Yes

No

$$
\begin{array}{lllll}
0.34 & 0.606 & 1 & 1.22 & 0.62-2.39
\end{array}
$$

$\begin{array}{lllll}9.36 & 0.003 & 1 & 2.24 & 1.33-3.76\end{array}$

$104 \quad 59(56.7 \%) \quad 45(43.3 \%)$

$138 \quad 51(37.0 \%) \quad 87(63.0 \%)$

$96 \quad 41(42.7 \%) \quad 55(57.3 \%)$

$137 \quad 67(48.9 \%) \quad 70(51.1 \%)$

$62 \quad 26(41.9 \%) \quad 36(58.1 \%)$

$34 \quad 15(44.1 \%) \quad 19(55.9 \%)$

$101 \quad 57(56.4 \%) \quad 44(43.6 \%)$

$137 \quad 50(36.5 \%) \quad 87(63.5 \%)$

$60 \quad 35(58.3 \%) \quad 25(41.7 \%)$

$41 \quad 22(53.7 \%) \quad 19(46.3 \%)$

\section{$\begin{array}{lllll}0.87 & 0.423 & 1 & 0.78 & 0.46-0.13\end{array}$}

$\begin{array}{lllll}0.05 & 1.000 & 1 & 0.92 & 0.39-2.13\end{array}$

$\begin{array}{lllll}9.34 & 0.003 & 1 & 2.26 & 1.34-3.81\end{array}$

$\begin{array}{lllll}0.22 & 0.686 & 1 & 1.21 & 0.55-2.69\end{array}$

$\mathrm{p}$ value based on Chi square test, $<0.05$ considered as significant association. * Among nurses who twisted their necks. ** Among nurses who bent their necks.

Table 10 Association between neck pain and psychosocial factors.

\begin{tabular}{|c|c|c|c|c|c|c|c|c|}
\hline \multirow[b]{2}{*}{ Factors } & \multicolumn{4}{|c|}{ Neck Pain } & \multirow[b]{2}{*}{ p value } & \multirow[b]{2}{*}{ df } & \multirow[b]{2}{*}{ POR } & \multirow[b]{2}{*}{ CI $95 \%$} \\
\hline & $\mathbf{n}$ & Yes n(\%) & No n $(\%)$ & $X^{2}$ & & & & \\
\hline Work Satisfaction & & & & 0.09 & 0.792 & 1 & 0.92 & $0.55-1.56$ \\
\hline Yes & 98 & $61(43.9 \%)$ & $78(56.1 \%)$ & & & & & \\
\hline No & 139 & $45(45.9 \%)$ & $53(54.1 \%)$ & & & & & \\
\hline Personnel shortage & & & & 11.89 & 0.001 & 1 & 2.54 & $1.45-4.45$ \\
\hline Yes & 154 & $82(53.2 \%)$ & $72(46.8 \%)$ & & & & & \\
\hline No & 84 & $26(31 \%)$ & $58(69 \%)$ & & & & & \\
\hline $\begin{array}{l}\text { Mental distress at } \\
\text { end of the workday }\end{array}$ & & & & 0.52 & 0.582 & 1 & 0.77 & $0.37-1.59$ \\
\hline Yes & 35 & $14(40 \%)$ & $21(60 \%)$ & & & & & \\
\hline No & 202 & $94(46.5 \%)$ & $108(53.5 \%)$ & & & & & \\
\hline Sufficient rest-time & & & & 0.17 & 0.773 & 1 & 0.89 & $0.51-1.57$ \\
\hline Yes & 067 & $29(43.3 \%)$ & $38(56.7 \%)$ & & & & & \\
\hline No & 173 & $80(46.2 \%)$ & $93(53.8 \%)$ & & & & & \\
\hline Co-workers support & & & & 0.65 & 0.429 & 1 & 0.81 & $0.48-1.36$ \\
\hline Yes & 139 & $60(43.2 \%)$ & $79(56.8 \%)$ & & & & & \\
\hline No & 97 & $47(48.5 \%)$ & $50(51.5 \%)$ & & & & & \\
\hline Supervisors support & & & & 0.04 & 0.878 & 1 & 1.06 & $0.58-1.95$ \\
\hline Yes & 182 & $82(45.1 \%)$ & $100(54.9 \%)$ & & & & & \\
\hline No & 55 & $24(43.6 \%)$ & $31(56.4 \%)$ & & & & & \\
\hline $\begin{array}{l}\text { Co-workers friendly } \\
\text { dealing }\end{array}$ & & & & 0.17 & 0.761 & 1 & 0.89 & $0.49-1.61$ \\
\hline Yes & 177 & $77(43.5 \%)$ & $100(56.5 \%)$ & & & & & \\
\hline No & 058 & $2746.6(\%)$ & $31(53.4 \%)$ & & & & & \\
\hline $\begin{array}{l}\text { Supervisors friendly } \\
\text { dealing }\end{array}$ & & & & 3.56 & 0.078 & 1 & 0.58 & $0.33-1.03$ \\
\hline Yes & 168 & $70(41.7 \%)$ & $98(58.3 \%)$ & & & & & \\
\hline No & 65 & $36(55.4 \%)$ & $29(44.6 \%)$ & & & & & \\
\hline
\end{tabular}

$\mathrm{p}$ value based on Chi square test, $<0.05$ considered as significant association. 
Table 11 Logistic regression of neck pain of registered female nurses in UKMMC.

\begin{tabular}{|c|c|c|c|c|c|c|c|c|c|}
\hline \multirow[b]{2}{*}{ Variables } & & \multirow[b]{2}{*}{ B } & \multirow[b]{2}{*}{ S.E. } & \multirow[b]{2}{*}{ Wald } & \multirow[b]{2}{*}{ df } & \multirow[b]{2}{*}{ Sig. } & \multirow[b]{2}{*}{$\operatorname{Exp}(\mathbf{B})$} & \multicolumn{2}{|c|}{$\begin{array}{l}\text { 95\% CI for } \\
\text { EXP(B) }\end{array}$} \\
\hline & & & & & & & & Lower & Upper \\
\hline \multirow{5}{*}{ Age } & & & & & & & & & \\
\hline & $50-59$ years & 1.144 & 0.923 & 1.536 & 1 & 0.215 & 3.138 & 0.514 & 9.153 \\
\hline & $40-49$ years & 0.855 & 0.416 & 4.228 & 1 & 0.040 & 2.351 & 1.041 & 5.311 \\
\hline & 30-39 years & 0.914 & 0.359 & 6.469 & 1 & 0.011 & 2.494 & 1.233 & 5.044 \\
\hline & $18-29$ years & \multicolumn{8}{|c|}{ Reference Group } \\
\hline \multirow{4}{*}{ BMI } & Obese & 0.601 & 0.396 & 2.307 & 1 & 0.129 & 1.825 & 0.840 & 3.964 \\
\hline & Overweight & 0.692 & 0.395 & 3.063 & 1 & 0.080 & 1.998 & 0.920 & 4.337 \\
\hline & Underweight & -1.291 & 0.995 & 1.683 & 1 & 0.194 & 0.275 & 0.039 & 1.934 \\
\hline & Normal & \multicolumn{8}{|c|}{ Reference Group } \\
\hline \multicolumn{2}{|c|}{ Physical Exercises } & & & & & & & & \\
\hline & No & 0.789 & 0.351 & 5.047 & 1 & 0.025 & 2.202 & 1.106 & 4.384 \\
\hline & Yes & \multicolumn{8}{|c|}{ Reference Group } \\
\hline \multicolumn{10}{|c|}{$\begin{array}{l}\text { Working Hours on } \\
\text { Computer/day }\end{array}$} \\
\hline & $>4$ hours & 0.694 & 0.317 & 4.790 & 1 & 0.029 & 2.001 & 1.075 & 3.725 \\
\hline & $\leq 4$ hours & \multicolumn{8}{|c|}{ Reference Group } \\
\hline \multicolumn{2}{|c|}{ Night Shifts/week } & 1.380 & 0.410 & 11.313 & 1 & 0.001 & 3.975 & 1.779 & 8.882 \\
\hline & No & \multicolumn{8}{|c|}{ Reference Group } \\
\hline \multicolumn{2}{|c|}{ Personnel Shortage } & & & & & & & & \\
\hline & Yes & 0.940 & 0.332 & 7.996 & 1 & 0.005 & 2.559 & 1.334 & 4.908 \\
\hline & No & \multicolumn{8}{|c|}{ Reference Group } \\
\hline \multicolumn{2}{|c|}{ Neck Bending } & & & & & & & & \\
\hline & Yes & 0.817 & 0.327 & 6.232 & 1 & 0.013 & 2.264 & 1.192 & 4.299 \\
\hline & No & \multicolumn{8}{|c|}{ Reference Group } \\
\hline Constant & & -4.038 & 0.645 & 39.188 & 1 & 0.000 & 0.018 & & \\
\hline
\end{tabular}

\section{Discussion.}

1. The prevalence rate of neck pain among registered female nurses.

In this cross sectional study, the point and period prevalence rates of the work related neck pain were $36 \%$ and $45.5 \%$ respectively of the respondents reported prevalent neck pain. In terms of point prevalence rate of neck pain during the past 1 month in this study is in agreement with other studies ${ }^{8+9}$. Other studies have reported both higher ${ }^{10+11}$ and lower ${ }^{12+13}$ point prevalence rates of neck pain. In terms of 12 months period prevalence rate of neck pain in this study is in agreement with other studies ${ }^{3+14+15+16+17+18+19+20}$. Also other studies have reported both higher ${ }^{21+22}$ and lower ${ }^{23+24} 12$ months period prevalence rates of neck pain.

However, the prevalence rates of WMSDs noted to vary across occupational groups and over national boundaries that could be due to variations and differences in subjectivity of terms, instruments or questionnaires, organizational work settings, cultural perception, sample sizes, response rate, cut-off points of some variables such as BMI and age groups, literature reviews and reporting of pain and healthy worker effect, all these were adduced for the variation in the prevalence rates of neck complaints in the different studies ${ }^{3+21}$.

\section{Association between neck pain and socio-demographic factors.}

In terms of age, in this study the majority of the respondents' age was fallen into age group 18-29 years $44.2 \%$. There were significant associations between age groups (30-39) and (40-49) years and neck pain. While while age group (50-59) years have showed no significant association. This reverse U-shaped association between age groups and neck pain was in agreement with other studies ${ }^{3+25+26+27}$. And could be explained as the risk of neck pain increased until the age of 50 and decreased slightly thereafter, and the increase with age could be understood by increasing degeneration of the cervical spine with age, and the decrease of neck pain in the oldest age group could be that chronic diseases and other ailments may gain the upper hand ${ }^{+3}$. Or could be explained as WMSDs increase with age and duration of employment. It was observed that after age 50 years and 
at greater than 20 years of clinical practice, the prevalence of WMSDs declined. The lower rate of WMSDs among the very senior nurses in terms of age and years of clinical practice may be attributed to less manual handling but more administrative duties that often come with rise in job cadre, while older nurses have increased level of knowledge about injury prevention, avoid harmful physical load, and have developed better coping strategies for musculoskeletal problems than the less experienced and younger nurses. And also healthy worker effect was also implicated for the inverse trend observed between lower prevalence of WMSDs and each of older age and higher clinical experience. Which could be described in cross sectional studies as a continuing selection process such that those who remain in an employment tend to be healthier over time that in turn would lead to attenuating an adverse effect of exposure and decreasing the observed associations between WMSDs and physically demanding jobs ${ }^{28+29+30}$.

In terms of BMI, the majority of the respondents' BMI fell into the obese category $36 \%$. Although there was a significant associations between BMI and the neck pain by using Chi square test, but logistic regression test, revealed that there was no significant. And the possible explanations could be due to work tasks and the homogeneous sample group as the respondents were females or could be due to the influence of other risk factors in logistic regression analysis, and the and this was in agreement with ${ }^{3+31+32+33}$.

Obesity is a disease which prevalent allover world that could be resulted from infrequent physical exercises, sedentary jobs such as prolonged office working hours, pregnancy, drugs intake side effects such as oral contraceptives and steroids or any other causes, and this will lead to accumulation of excess fat in any body part such as neck region; a narrow area that result in soft tissues and nerves compression that in turn lead to pain in neck region, and the obese women and men have an approximately $20 \%$ more chance of having chronic musculoskeletal pain ${ }^{34+35}$.

In terms of race, majority of the the respondents were Malay $44.7 \%$. And there was a no significant association between race and the neck pain by using Chi square test and logistic regression test. And almost all studies revealed no significant relationship between race and the neck pain, and the variance of the prevalence rates of neck pain among populations were due to physical inactivity, BMI, eating habit, alcoholism or smoking ${ }^{36+37}$.

\section{Association between neck pain and work related factors.}

In terms of categorised into 5 working departments as abovementioned, by using Chi square test there was no significant relationship between the neck pain and the working departments in present study. However, the 12 months prevalence rates of neck pain among according to working departments of UMKCC in medical departments, surgical departments, anesthesia and intensive care department, nursing management and emergency department were $39.3 \%, 56.9 \%, 43.8 \%, 35.3 \%$ and $60 \%$ respectively. This insignificant relationship could be explained that present study focused on computer using related risk factors of the neck pain rather than other risk factors of the neck pain itself such as excessive force use in lifting patients in bed and transferring patients out of bed because excessive force use could cause neck pain indirectly due to trapezium muscle stretching affect that in turn could cause shoulder and neck pain. In present study was focusing on neck pain risk factors in terms of computer using, however, high prevalence rates of neck pain were high surgical, anesthesia and intensive care and emergency departments where the excessive force use is common which is in agreement with other studiesThis was in agreement with other study ${ }^{10+38+39}$.

In terms of working duration, there was no significant relationship between the neck pain and the working duration in present study by using Chi square test. And this insignificant relationship could be explained be due to short employment duration of the majority of newly recruited registered female nurses according to nursing management department of UKMMC data base which was in agreement with other study ${ }^{40}$.

However, the association between the neck pain and the employment duration could be explained according to NIOSH 1997) one of the risk components of cumulative WMSDs is the length of exposure duration or could be explained the ageing process and muscular strain due to computer uses ${ }^{26+30+40+41}$.

In terms of night shifts, there was significant relationship between neck pain and night shifts in this study by using Chi square test and logistic regression test. And this significant association could be explained either according to NIOSH 2012 and other studies ${ }^{15+18}$ as the working at night shifts could lead to muscle weakness which in turn lead to lack of support to the all joints of the body and as a consequence the risk of initial fatigue and overexertion injury will be increased or the day shifts were far more demanding the number of activities related to patients' care than afternoon and night shifts which in turn could make the number of nurses in charge during night shifts to be substantially lower than during day shifts and impose an overload and affect the health of the nurses ${ }^{42+43}$.

\section{Association between neck pain and lifestyle factors.}

In this study, the prevalence rate of the neck pain among registered female nurses who were smokers was $33.3 \%$; 3 out of 242 respondents have reported that they were smokers, and Chi square test showed a 
statistically insignificant association between the neck pain and the smoking, which was in agreement with other studies $^{3+11+33}$. And the possible explanation of this insignificant association could be due to the majority of registered female nurses in UKMMC were not smoking.

The objectives of studying the smoking in present study were to corroborate efficiency and effectiveness of anti-smoking educating messages on smoking harmful health effects that have provided by the nurses, doctors and teaching staff $\mathrm{ft}^{4}$ and to highlight awareness and perception of Malaysians about health risks of smoking. Malaysia like other Islamic countries, the smoking among females $1.6 \%$ could be considered as social stigma comparing with the males $46.4 \%$ according to WHO 2011 report on the global tobacco epidemic; therefore there was an insignificant association between neck pain and smoking as it was already expected. However, other studies showed that there is association between WMSDs and smoking ${ }^{45}$.

In terms of physical exercises, there was significant association between the neck pain and regular doing physical exercises at least 3 times per week ${ }^{6+7}$ by using Chi square test and logistic regression test. The prevalence rate of the neck pain among the respondents was more than half, $52.1 \%$ of them did not do physical exercises regularly. And the possible explanation could be that the lack of physical exercises lead to muscle weakness which in turn lead to lack of support to the all joints of the body and as a consequence the risk of initial fatigue and overexertion injury will be increased ${ }^{45+46+47}$. And this significant association was in agreement with other studies ${ }^{41+48+49}$.

Generally there is no public widespread knowledge about physical exercises recommendations, as a survey done in USA by Centers for Disease Control and Prevention and American College of Sports Medicine among people knowledge about these recommendations showed that only third of them had accurate knowledge, therefore there was a need for more effective campaigns to promote physical activity among the people ${ }^{50}$.

\section{Association between neck pain and ergonomic factors.}

The studying of awkward neck postures in this study was done in terms of awkward bent and twisted neck postures. The 12 months prevalence rate of neck pain among the respondents who bent their necks was $56.4 \%$. And statistically there was a significant association between neck bending and the neck pain by using Chi square test and logistic regression test. In this study according to OSHA guidelines 2008, the distance of computer's display, using copyholder and arm resting on table which could cause or be related with neck bending. The majority of the respondents $82.6 \%$ did not use copyholder, $63.6 \%$ reported that the distance of computer's display was not at their own arm's length from their eye level, which could make them to extend forward or flex forward necks, and this which was in agreement with other studies ${ }^{3+51+52+53}$.

The explanation of this significant association; first, could be due to the muscles and ligaments around cervical joints were stretched or compressed during neck extension or flexion forward ${ }^{51}$, second, could be explained due to these increased neck flexion angles were associated with increased upper trapezius muscle activity and with neck and shoulder discomfort in office workers, and the neck pain was twice as likely for those sitting in poor posture with the head in a flexed forward position ${ }^{3+52}$, or third, could be explained due to the lower display heights the more head and neck flexion with more spinal asymmetry when working on computer $^{53+54}$.

The 12 months prevalence rate of neck pain among the respondents who twisted their necks was 42.7\%. And statistically there was no significant association between neck twisting and the neck pain by using Chi square test. The studying of awkward twisted neck posture was done in this study to determine the association between neck twisting and the neck pain, to corroborate the association of the computer's display position to the users and the neck pain. And the explanation of this insignificant association between the neck twisting and the neck pain; first, could be explained due to monitor placement with respect to the eyes of the users as most of the nurses $51.7 \%$ have reported that computer's display position was in front of them ${ }^{55}$ or second, could be explained due to small sample size of study, most of the respondents, $44.2 \%$ were in young (18-29) age group or the short observation periods that made the results less meaningful than they could be in a more elaborate study ${ }^{56}$.

Furthermore, according to Norwegian National Institute of Occupational Health examination evidence report on the systematic review of association between the computer work and WMSDs of the neck and upper extremity disorders stated that the results of 22 studies ( 26 articles) have showed limited evidence for a causal relationship between computer work per se, computer mouse and keyboard time related to a diagnosis of tension neck syndrome, forearm disorders and wrist, and insufficient evidence was found for an association between other WMSDs diagnoses of the neck and upper extremities, and have concluded that there was a limited epidemiological evidence for an association between aspects of computer work and some of the studied clinical diagnoses, and none of the evidence was considered as moderate or strong so there is a need for more and better documentation ${ }^{57}$.

In terms of repetitive movements of neck, there was no significant association between the neck pain and the repetitive bending and twisting movements of neck by using Chi square test. which was in agreement 
with some studies ${ }^{58}$. In this study, associations of repetitive neck movements and awkward neck postures with neck pain was studied, and the repetitive neck movements studying was limited to the respondents who kept their necks in awkward bent or twisted postures which in turn minimized the number of respondents in this study. And this done due to according to other studies ${ }^{59+60}$ prolonged neck bending and repetitive movement were associated more with shoulder pain or neck \& shoulder pains together so to proof this tripartite association, repetitive movements was limited to those who kept their neck in awkward postures.

The muscles in the neck and shoulder regions usually act as stabilizers and static contraction of the trapezius and other shoulder muscles are needed to keep the arms at right angles. This contraction is accentuated when there is also rotation or bending of the neck when the computer screen is placed to the side of the worker, not in front which is the recommended position, and the neck pain was twice as likely for those sitting in poor posture with the head in a flexed forward position ${ }^{3}$.

In terms of working hours on computer, there was significant relationship between the neck pain and the prolonged working hours; more than 4 hours on computer by using Chi square test and logistic regression test. And 12 months prevalence rate of the neck pain among respondents who spent more than four hours on computer was $56.7 \%$. And this significant association could be explained as remaining seated for long periods, usually accompanied by curvature of the spine, increases pressure on cervical vertebra discs, ligaments, and muscles of the neck and upper limbs ${ }^{61}$. And Many studies have showed that the duration of computer use, frequency of breaks, method of keyboard operation, position of computer monitors, type and use of input devices were associated with neck pain at work, and taking mini breaks of 30 seconds once every 20 to 40 minutes is an effective means to reduce neck pain at work and these short breaks with no adverse effect on productivity ${ }^{4+62+63}$.

\section{Association between neck pain and psychosocial factors.}

Among many psychosocial risk factors of WMSDs complaints, work satisfaction, personnel shortage, mental tiredness at the end of workday, sufficient break-time, co-workers support, supervisors support, coworkers' friendly dealing and supervisors' friendly dealing factors were done $3+31$ which which showed $43.9 \%$, $53.2 \%, 40 \%, 43.3 \%, 43.2 \%, 45.1 \%, 43.5$ and $41.7 \%$ respectively 12 months prevalence rates of neck pain among respondents. However, only personnel shortage showed significant association with the neck pain by using Chi square test and logistic regression test.

This significant association could be explained as that the personnel shortage might was an indirect reflection of work overload which was in agreement with consistent evidences in previous cross sectional and longitudinal studies ${ }^{3+26+64}$.

According to other psychosocial risk factors, even though they were not significant statistically but showed marked 12 months prevalence rate of the neck pain, which could be explained as when the physical demands an included in a model of WMSDs complaints, the significance of psychological demands will be disappeared ${ }^{65}$, or could be explained according to (Rahmah et al 2008) as the psychosocial risk factors could affect the risk of injury, severity and healing process. And by taking mini breaks of 30 seconds once every 20 to 40 minutes will allow a reduction in computer exposure and permit muscle relaxation without adverse effect on worker productivity ${ }^{61+62}$. However, in a cross sectional survey it is difficult to determine whether the pain proceeds or follows the psychological symptoms.

\section{Neck Pain Severity.}

As abovementioned in table 1 the results of neck pain severity in terms of working departments in last month in this study between 15 September and 15 October 2012 is to some extent in agreement with a study was done in Turkey among the nurses, to determine the prevalence rates and the risk factors of WMSDs of low back, shoulder and neck complaints, and the results have showed that and the nurses who were working in the departments of general surgery and obstetrics \& gynecology had more WMSDs complaints than the nurses in other departments ${ }^{10}$. Also neck pain disability have assessed through neck pain interfering with daily work activities according to study in Belgium ${ }^{3}$,and in this study the respondents have reported that neck pain interfered with their activities from minimum one day to maximum three weeks, on average one neck pain have interfered them about 7 days in doing their daily work activities during working hours, regardless the working departments.

\section{Economic Burden of Sick leave due to Neck Pain.}

Work related neck pain in present study population caused a rate of sick leave in the past 12 months of 42 days, which ranged from one to three days, and according to Malaysian salary schedule 2012 data base in nursing management department in UKMMC; the basic salary of nurses with diploma in nursing and degree in nursing start from $1780.34 \mathrm{RM}$ and $2274 \mathrm{RM}$ with annual bonus about $36 \mathrm{RM}$ and $100 \mathrm{RM}$ respectively. 
According to present study, the most of respondents had diploma in nursing $88.8 \%$, so the cost of each day of sick leave will be according to them, and the employment duration ranged from one to seventeen years, and as abovementioned nurses with diploma in nursing their basic salary was 1780.34 RM (about 60 RM per day) for those who have employment duration of one year and 2206.11 RM (about 74 RM per day) for those who have employment duration of seventeen years. And average of them will be 67 RM per day (60 RM plus 74 RM divided by 2), so cost of one day sick leave due to neck pain was $67 \mathrm{RM}$.

Generalizing this feature to the overall nurses' population in Malaysia would yield considerable lost working days during the preceding year. This estimation indicates that in this occupation "nursing", regardless of indirect costs and negative effects of work related neck pain on quality of services and productivity, work related neck pain have caused pronounced direct costs in the form of lost working days ${ }^{66}$.

\section{Conclusion.}

In this study registered female nurses; the respondents reported a 1 month point prevalence rate from 15 of September to15 of October 2012, 36\% and 12 month period prevalence rate, 45.5\% of neck pain, which was compatible with many other studies, the variables that have been studied in terms of literature review of present study in Chi square test and that showed a significant relationship with neck pain were age, BMI, physical exercises, working time on computer, night shifts, personnel shortage and neck bending, while logistic regression showed the variables had significant relationship with neck pain of registered female nurses were; age groups 30-39 $(p=0.011)$ and 40-49 $(p=0.040)$, physical exercises $(p=0.025)$, working time on computer $(p=0.029)$, night shifts $(p=0.001)$, personnel shortage $(p=0.005)$ and neck bending $(p=0.013)$.

Furthermore, (10.7\%) of the respondents had medical leave from work due to neck pain and only (4.5\%) of them have changed their work because of neck pain, and lastly $(16.5 \%)$ of registered female nurses with neck pain had minimal hindrance or disability which have meant the daily life activities performance without any difficulties.

Although this study was unable to conclude significant result to several factors, other research has concluded association between those factors with neck pain such as BMI, repetitive neck movements, working department, most of psychosocial risk factors. The reasons could be due to small sample size of the study and it was also homogenous in term of gender.

\section{Recommendations.}

Based on the present study results suggest that effective intervention strategies aiming at reducing the occurrence of neck pain most likely have to take into account both ergonomic improvements, psychosocial work factors and cognitive behavioural aspects. Intervention should be applied to reduce computer exposure and also toward improving ergonomic conditions. Dynamic and sit/stand chairs will lead to more variation in posture and comfort. The use of document holders, a correct placement of the screen and adjustable chairs will reduce the neck load.

Ergonomic studies were done years ago have indicated that a correct placement of the screen, adjustable chairs and keyboard and document holders use were important factors in providing a comfortable work environment and preventing a broad range of computer use associated WMSDs such as eye, neck and back strain, fatigue, headaches, and wrist, hand, elbow and shoulder disorders, also have showed dramatically improvements through use of good ergonomic designs.

Ergonomic healthy education programs designing to raise knowledge about safe work practice through introducing a message to the studied registered female nurses who are computer users about the right manner of safe ergonomic practice accompanied with illustration of ergonomic posture for computer users which is advised to be such as top of monitor at or just below eye level, shoulder relaxed, and elbows close to body and arm supported and wrists in line with forearms and feet flat on the floor.

Arranging for task variation and job and worker rotation, rearrange workstation and providing work station with ergonomic chairs like Aeron and Exercise Ball chairs and workstation accessories such as document holder, footrest and wrist rest. The approach of ergonomic principles and bio-mechanics education and training programs of proper computer using in the work stations, that kind of knowledge for the frontline health care providers can improve the working environment and as a consequence preventing injury and promoting safe work place are also very important in work place.

Nurses can be advised to do regular exercises to strengthen their muscles at least three times per week for minimum twenty minutes, engaging computer users in physical activity as part of their work day would be an appropriate prevention strategy, and encouraging leisure activities may be beneficial in sedentary workers because physical activity facilitates both mechanical and metabolic processes that are healing for musculoskeletal tissues. 
Taking mini breaks of 30 seconds once every 20 to 40 minutes is an effective means to reduce neck pain at work and these short breaks have no adverse effect on worker productivity, also nurses can be advised to do neck exercises during working hours ${ }^{62}$.

Employers should ensure ergonomic adjustment in work places to reduce the risk of neck symptoms or injury such as adapting "The Take-a-Stand" project and using Ergotron sit-stand workstations products to meet the physical needs of workers which creates a work environment that promotes wellness while improving productivity; Ergotron is a member of the human factors and ergonomics society, reflecting dedication to workplace wellness while contributing to the study of ergonomic ${ }^{67}$.

Employers may be able to reduce neck pain in the workplace by increasing the collective decision making of employees, and insuring that workers have support from superiors when making decisions.

The psychosocial risks faced by nurses require attention in order to prevent the progression of prolonged work related pain into work instability which could lead to work related disability ${ }^{68+69}$.

\section{References.}

[1] Mody, G. M. \& Woolf, A. D. 2003. The Global Burden of Musculoskeletal Disorders. European pharmacotherapy.136-141.

[2] Hogg-Johnson S, van der Velde G, Carroll LJ, Holm LW, Cassidy JD, Guzman J, et al 2009; the burden and determinants of neck pain in the general population: results of the Bone and joint Decade 2000-2010 Task Force on Neck Pain and Its Associated Disorders. Manipulative Physiological Theory, 32 (2Suppl):S46-S60.

[3] Cagnie B, Danneels L, Van Tiggelen D, De Loose V, Cambier D. 2007; Individual and work-related risk factors for neck pain among office workers: a cross sectional study. Euro Spine Journa,l 16 (5):679-686.

[4] Eltayeb SM, Staal JB, Khamis AH, de Bie RA. 2011; Symptoms of neck, shoulder, forearms, and hands: a cohort study among computer office workers in Sudan. Journal of Clinical Pain, 27 (3):275-281.

[5] Ijmker S, Blatter BM, van der Beek AJ, van Mechelen W, Bongers PM. 2006;Prospective research on musculoskeletal disorders in office workers (PROMO): study protocol. BMC Musculoskeletal Disorders, 7:55.

[6] American Academy of Family Physician. 1995. Exercise How To Get Started. (Online) Http:familydoctor.org (4 March 2011).

[7] Ylinen JJ, Takala EP, Nykänen MJ, Kautiainen HJ, Häkkinen AH, Airaksinen OVP, et al. 2006;Effects of twelve-month strength training subsequent to twelve-month stretching exercise in treatment of chronic neck pain. Journal of Strength Conditioning Research, 20 (2):304-308.

[8] Yeung, S. S., Genaidy, A., Deddens, J., \& Sauter, S. 2005. The relationship between protective and risk characteristics of acting and experienced workload, and musculoskeletal disorder cases among nurses. Journal of Safety Research, 36(1), 85-95. doi: $10.1016 /$ j.jsr.2004.12.002.

[9] Ando, S., Ono, Y., Shimaoka, M., Hiruta, S., Hattori, Y., \& Hori, F., et al. 2000. Associations of self estimated workloads with musculoskeletal symptoms among hospital nurses. Occupational and Environmental Medicine, 57(3), 211-216.

[10] Tezel, A. 2005. Musculoskeletal Complaints among a Group of Turkish Nurses. Journal of Neuroscience, 115: 871-880.

[11] Erikson W., Natvig B., Knardahl S., et al 1999: Job Characteristics as predictors of neck pain, a 4-year prospective study. J. Occupational \& Environmental Medicine, 41: 893-902.

[12] Picavet, H. S. J., \& Schouten, J. S. A. G. 2003. Musculoskeletal pain in the Netherlands: prevalences, consequences and risk groups, the DMC(3)-study. Pain, 102(1-2), 167-178.

[13] Ahlberg-Hultén, G. K., Theorell, T., \& Sigala, F. 1995. Social support, job strain and musculoskeletal pain among female health care personnel. Scandinavian Journal of Work, Environment \& Health, 21(6), 435-439.

[14] Lagerström, M., Wenemark, M., Hagberg, M., \& Hjelm, E. W. (1995). Occupational and individual factors related to musculoskeletal symptoms in five body regions among Swedish nursing personnel. International Archives of Occupational and Environmental Health, 68(1), 27-35.

[15] Trinkoff, A. M., Lipscomb, J. A., Geiger-Brown, J. \& Brady, B. 2002. Musculoskeletal problems of the neck, shoulder, and back and functional consequences in nurses. Abstract. American Journal of Industrial Medicine, 41(3): 170-178.

[16] Guez, M., Hildingsson, C., Nilsson, M., \& Toolanen, G. 2002. The prevalence of neck pain: a population-based study from northern Sweden. Acta Orthopaedica Scandinavica, 73(4), 455-459. Doi: 10.1080/00016470216329.

[17] Alexopoulos, E. C., Burdorf, A., \& Kalokerinou, A. (2003). Risk factors for musculoskeletal disorders among nursing personnel in Greek hospitals. International Archives of Occupational and Environmental Health, 76(4), 289-294. doi:10.1007/s00420-003-0442-9

[18] Smith, D.R., Wei, N., Zhao, L. \& Wang, R.S. 2004a. Musculoskeletal Complaints and Psychosocial Risk Factors Among Chinese Hospital Nurses. Oxford Journals, 54: 579-582.

[19] Smith, D. R., Wei, N., Kang, L., \& Wang, R. S. 2004b. Musculoskeletal disorders among professional nurses in mainland China. Journal of Professional Nursing: Official Journal of the American Association of Colleges of Nursing, 20(6), 390-395.

[20] Juul-Kristensen, B., \& Jensen, C. 2005. Self-reported workplace related ergonomic conditions as prognostic factors for musculoskeletal symptoms: the "BIT" follows up study on office workers. Occupational and Environmental Medicine, 62(3), 188194. doi:10.1136/oem.2004.013920

[21] Smith, D. R., Kondo, N., Tanaka, E., Tanaka, H., Hirasawa, K., \& Yamagata, Z., et al. 2003. Musculoskeletal disorders among hospital nurses in rural Japan. Rural and Remote Health, 3(3), 241.

[22] Lipscomb, J., Trinkoff, A., Brady, B., \& Geiger-Brown, J. 2004. Health care system changes and reported musculoskeletal disorders among registered nurses. American Journal of Public Health, 94(8), 1431-1435.

[23] Smith, D. R., Mihashi, M., Adachi, Y., Koga, H., \& Ishitake, T. 2006. A detailed analysis of musculoskeletal disorder risk factors among Japanese nurses. Journal of Safety Research, 37(2), 195-200. doi:10.1016/j.jsr.2006.01.004.

[24] Harcombe, H., McBride, D., Derrett, S., \& Gray, A. 2009. Prevalence and impact of musculoskeletal disorders in New Zealand nurses, postal workers and office workers. Australian and New Zealand Journal of Public Health, 33(5), 437-441. doi:10.1111/j.1753-6405.2009.00425.

[25] Leclerc, A., Niedhammer, I., Landre, M. F., Ozguler, A., Etore, P., \& Pietri-Taleb, F., et al. 1999. One-year predictive factors for various aspects of neck disorders. Spine, 24(14), 1455-1462.

[26] Viikari-Juntura, E., Martikainen, R., Luukkonen, R., Mutanen, P., Takala, E. P., \& Riihimäki, H et al 2001. Longitudinal study on work related and individual risk factors affecting radiating neck pain. Occupational and Environmental Medicine, 58(5), 345-352. 
[27] Bot, S. D. M., van der Waal, J. M., Terwee, C. B., van der Windt, D. A. W. M., Schellevis, F. G., \& Bouter, L. M., et al 2005. Incidence and prevalence of complaints of the neck and upper extremity in general practice. Annals of the Rheumatic Diseases, 64(1), 118-123. doi:10.1136/ard.2003.019349.

[28] Arrighi, H. M., \& Hertz-Picciotto, I. 1994. The evolving concept of the healthy worker survivor effect. Epidemiology (Cambridge, Mass.), 5(2), 189-196.

[29] Shah, D. 2009. Healthy worker effect phenomenon. Indian Journal of Occupational and Environmental Medicine, 13(2), 77-79. doi:10.4103/0019-5278.55123.

[30] Tinubu, B. M. S., Mbada, C. E., Oyeyemi, A. L., \& Fabunmi, A. A. 2010. Work-related musculoskeletal disorders among nurses in Ibadan, South-west Nigeria: a cross-sectional survey. BMC Musculoskeletal Disorders, 11, 12. Doi: 10.1186/1471-2474-11-12.

[31] Rahmah, M.A., Rozy, J., Halim, I., Jamsiah, M. \& Shamsul, A.S. 2008. Prevalence of Back Pain Among Nurses in Government Health Clinic and Hospital in Port Dickson, Malaysia. Journal of Community Health.14 (2): 11-18.

[32] Kitzmann AS, Fethke NB, Baratz KH, Zimmerman MB, Hackbarth DJ, Gehrs KM, et al 2011;A Survey Study of Musculoskeletal Disorders Among Eye Care Physicians Compared with Family Medicine Physicians. Ophthalmology.

[33] Iizuka, Y., Shinozaki, T., Kobayashi, T., Tsutsumi, S., Osawa, T., \& Ara, T., et al. 2012. Characteristics of neck and shoulder pain (called katakori in Japanese) among members of the nursing staff. Journal of Orthopedic Science : Official Journal of the Japanese Orthopedic Association, 17(1), 46-50. Doi: 10.1007/s00776-011-0177-5.

[34] Webb R, Brammah T, Lunt M, Urwin M, Allison T, Symmons D, et al 2003; Prevalence and predictors of intense, chronic and disabling neck and back pain in the UK general population. Journal of Pain, 28 (11):1195-1202.

[35] Nilsen TIL, Holtermann A, Mork PJ. 2011;Physical exercise, body mass index, and risk of chronic pain in the low back and neck/shoulders: longitudinal data from the Nord-Trondelag Health Study. American Journal of Epidemiology, 174 (3):267-273.

[36] Carey TS, Freburger JK, Holmes GM, Jackman A, Knauer S, Wallace A, et al 2010; Race, care seeking, and utilization for chronic back and neck pain: population perspectives. Journal of Pain, 11 (4):343-350.

[37] Jørgensen MB, Rasmussen CDN, Carneiro IG, Flyvholm MA, Olesen K, Ekner D, et al 2011; Health disparities between immigrant and Danish cleaners. Int. Arch Occupational and Environmental Health, 84 (6):665-674.

[38] Bos, E., Krol, B., van der Star, L., \& Groothoff, J. (2007). Risk factors and musculoskeletal complaints in non-specialized nurses, IC nurses, operation room nurses, and X-ray technologists. International Archives of Occupational and Environmental Health, 80(3), 198-206. Doi: 10.1007/s00420-006-0121-8.

[39] Alrowayeh, H.N., Alshatti, T.A., Aljadi, S.H., Fares, M., Alshamir, M.N. \& Alwazan, S.S. 2010. Prevalence, Characteristics and Impact of Musculoskeletal Disorders: A Survey Among .Physical Therapists in The State of Kuwait. BMC Musculoskeletal disorders, 11(16): 1-11.

[40] Adegoke, B.OA., Akodu, A.K. \& Oeyemi, A.L. 2008. Work-related Musculoskeletal Disorder Among Nigerian Physiotherapists. BMC Musculoskeletal Disorders, 9(112): 1-9.

[41] Ghasemkhani, M., Mahmudi, E., \& Jabbari, H. 2008. Musculoskeletal symptoms in workers. International Journal of Occupational Safety and Ergonomics: Jose, 14(4), 455-462.

[42] Gonçalves, M. B., Fischer, F. M., Lombardi Júnior, M., \& Ferreira, R. M. 2001. Work activities of practical nurses and risk factors for the development of musculoskeletal disorders. Journal of Human Ergology, 30(1-2), 369-374.

[43] Takahashi, M., Iwakiri, K., Sotoyama, M., Hirata, M., \& Hisanaga, N et al 2009. Musculoskeletal pain and night shift naps in nursing home care workers. Occupational Medicine (oxford. England), 59(3), 197-200. doi:10.1093 /occmed/kqp029.

[44] Zawahir, S., Omar, M., Awang, R., Yong, H. H., Borland, R., \& Sirirassamee, B., et al. 2012. Effectiveness of Antismoking Media Messages and Education Among Adolescents in Malaysia and Thailand: Findings From the International Tobacco Control Southeast Asia Project. Nicotine \& Tobacco Research: Official Journal of the Society for Research on Nicotine and Tobacco, doi:10.1093/ntr/nts161.

[45] Korhonen T, Ketola R, Toivonen R, Luukkonen R, Häkkänen M, Viikari-Juntura E, et al. 2003;Work-related and individual predictors for incident neck pain among office employees working with video display units. Occupational Environmental medicine, $60(7): 475-482$.

[46] Hildebrandt VH, Bongers PM, Dul J, van Dijk FJ, Kemper HC. 2000; Relationship between leisure time, physical activities and musculoskeletal symptoms and disability in worker populations. International Arch Occupational Environmental Health, 73 (8):507518.

[47] Lorusso, A., Bruno, S., \& L'Abbate, N. 2007. A review of low back pain and musculoskeletal disorders among Italian nursing personnel. Industrial Health, 45(5), 637-644.

[48] Nevala-Puranen, N., Pakarinen K. and Louhevaara, V. 2003: Ergonomic intervention on neck, shoulder and arm symptoms of newspaper employees in work with visual display unit. International Journal of Industrial Ergonomics, 31: 1-10.

[49] Carroll L.J., Hogg Johnson S., Cote P., et al. 2008 Course and prognostic factors for neck pain in workers. Results of the Bone and Joint decade 2000-2010 task force of neck pain and its associated disorders. Spine, 33 Suppl.: 93-100.

[50] Bennett, G. G., Wolin, K. Y., Puleo, E. M., Mâsse, L. C., \& Atienza, A. A. 2009. Awareness of national physical activity recommendations for health promotion among US adults. Medicine and Science in Sports and Exercise, 41(10), 1849-1855. doi:10.1249/ MSS.0b013e3181a52100.

[51] Chaffin D, Andersson G, Martin B. 2006; Occupational Biomechanics (4thEdition), Journal of Wiley \& New York.

[52] David, G., Woods, V., Li, G., \& Buckle, P. 2008. The development of the Quick Exposure Check (QEC) for assessing exposure to risk factors for work-related musculoskeletal disorders. Applied Ergonomics, 39(1), 57-69. doi:10.1016/ j.apergo.2007.03.002.

[53] Straker, L., Burgess-Limerick, R., Pollock, C., Murray, K., Netto, K., \& Coleman, J., et al 2008. The impact of computer display height and desk design on 3D posture during information technology work by young adults. Journal of the International Society of Electrophysiological Kinesiology, 18(2), 336-349. doi:10.1016/j.jelekin.2006.10.007.

[54] Saito, S., Miyao, M., Kondo, T., Sakakibara, H., \& Toyoshima, H. 1997. Ergonomic evaluation of working posture of VDT operation using personal computer with flat panel display. Industrial Health, 35(2), 264-270.

[55] Gerr, F., Marcus, M., Ortiz, D., White, B., Jones, W., \& Cohen, S., et al 2000. Computer users' postures and associations with workstation characteristics. Aihaj : a Journal for the Science of Occupational and Environmental Health and Safety, 61(2), 223-230.

[56] Ankrum, D.R. et al 1997. A challenge to eyelevel, perpendicular-to-gaze, monitor placement. In Proceedings of the 13th Triennial Congress of the International Ergonomics Association Vol. Pp Helsinki Finnish Institute of Occupational Health, 5, 35-38.

[57] Waersted, M., Hanvold, T. N., \& Veiersted, K. B. 2010. Computer work and musculoskeletal disorders of the neck and upper extremity: a systematic review. Bmc Musculoskeletal Disorders, 11, 79. Doi: 10.1186/1471-2474-11-79.

[58] Ariëns, G. A., van Mechelen, W., Bongers, P. M., Bouter, L. M., \& van der Wal, G. 2000. Physical risk factors for neck pain. Scandinavian Journal of Work, Environment \& Health, 26(1), 7-19. 
[59] Sood, D., Nussbaum, M. A., \& Hager, K. 2007. Fatigue during prolonged intermittent overhead work: reliability of measures and effects of working height. Ergonomics, 50(4), 497-513. Doi: 10.1080/00140130601133800.

[60] Waters, T., Collins, J., Galinsky, T., \& Caruso, C. 2006. NIOSH research efforts to prevent musculoskeletal disorders in the healthcare industry. Orthopedic Nursing / National Association of Orthopedic Nurses, 25(6), 380-389.

[61] Ortiz-Hernández, L., Tamez-González, S., Martínez-Alcántara, S., \& Méndez-Ramírez, I. 2003. Computer use increases the risk of musculoskeletal disorders among newspaper office workers. Archives of Medical Research, 34(4), 331-342. Doi: 10.1016/S01884409(03)00053-5.

[62] Menzel, N. N. 2007. Psychosocial factors in musculoskeletal disorders. Critical Care Nursing Clinics of North America, 19(2), $145-$ 153. doi:10.1016/j.ccell. 2007.02.006.

[63] Johnston, V., Souvlis, T., Jimmieson, N. L., \& Jull, G. 2008. Associations between individual and workplace risk factors for selfreported neck pain and disability among female office workers.Applied Ergonomics, 39(2), 171-82.doi:10.1016/j.apergo. 2007.05.011.

[64] Aasa, U., Barnekow-Bergkvist, M., Angquist, K. A., \& Brulin, C. 2005. Relationships between work-related factors and disorders in the neck-shoulder and low-back region among female and male ambulance personnel. Journal of Occupational Health, 47(6), 481489.

[65] Kerr MS, Frank JW, Shannon HS, Norman RW, Wells RP, Neumann WP, Bombardier C. 2001Biomechanical and psychological risk factors for low back pain at work. American Journal Public Health, 91:1069-75.

[66] Choobineh, A., Movahed, M., Tabatabaie, S. H., \& Kumashiro, M. 2010. Perceived demands and musculoskeletal disorders in operating room nurses of Shiraz city hospitals. Industrial Health, 48(1), 74-84.

[67] Pronk, N. P., Katz, A. S., Lowry, M., \& Payfer, J. R. 2012. Reducing Occupational Sitting Time and Improving Worker Health: The Take-a-Stand Project, 2011. Preventing Chronic Disease, 9, E154. doi:10.5888.pcd9.110323.

[68] Gilworth, G., Bhakta, B., Eyres, S., Carey, A., Anne Chamberlain, M., \& Tennant, A., et al. 2007. Keeping nurses working: development and psychometric testing of the Nurse-Work Instability Scale (Nurse-WIS). Journal of Advanced Nursing, 57(5), 543551. doi: $10.1111 / \mathrm{j} .1365-2648.2006 .04142$.

[69] Letvak, S., \& Ruhm, C. J. 2010. The impact of worker health on long term care: implications for nursing managers. Geriatric nursing New York, 31(3), 165-169 doi: 10.1016/j.gerinurse.2010.03.002. 